\title{
Longitudinal Monitoring of Listeria monocytogenes Contamination Patterns in a Farmstead Dairy Processing Facility
}

\author{
A. J. Ho, V. R. Lappi, ${ }^{1}$ and M. Wiedmann ${ }^{2}$ \\ Department of Food Science, Cornell University, Ithaca, NY 14853
}

\begin{abstract}
Contamination of dairy products with Listeria monocytogenes is a concern because multiple human listeriosis outbreaks have been linked to contaminated cheese and dairy products. Dairy production on farmstead operations may be a particular concern because $L$. monocytogenes is also an animal pathogen that can be shed by ruminants with and without clinical symptoms; physical proximity between production animal and dairy processing facilities may thus provide a higher risk for introduction of $L$. monocytogenes into the dairy production process. To better understand the risks of L. monocytogenes contamination associated with farmstead dairy production, samples from a farmstead dairy processing operation and the milking barn of the directly adjacent dairy sheep operation were tested for $L$. monocytogenes over a 3-yr period. Prevalence of $L$. monocytogenes for samples collected on the farm $(\mathrm{n}=$ $85)$ and the dairy production facility $(\mathrm{n}=674)$ was 9.4 and $2.7 \%$, respectively. Molecular subtyping using automated EcoRI ribotyping of $L$. monocytogenes isolates revealed that distinct subtypes were associated with the dairy production facility and the farm's milking parlor. Although a total of 5 and 4 different ribotypes were identified among isolates obtained from the dairy production facility and the milking parlor, respectively, only 1 ribotype (DUP-1030A) was isolated from both. Different ribotypes were predominant among isolates from the dairy production facility (ribotype DUP1052A, representing 15 of 18 isolates) and the farm's milking parlor (ribotype DUP-1039A, representing 4 of 8 isolates); each of these ribotypes appeared to persist over time in the respective area. Our data support that i) in farmstead dairy processing facilities, L. monocytogenes present on the farm can largely be prevented from being introduced into the processing facility; and ii) $L$. monocytogenes can persist on farm and in processing
\end{abstract}

Received June 23, 2006.

Accepted January 8, 2007.

${ }^{1}$ Current address: Minnesota Department of Health, Public Health Laboratories, St. Paul 55164.

${ }^{2}$ Corresponding author: mw16@cornell.edu areas, providing a potential high-risk source for contamination. Preventing cross contamination between dairy production and processing facilities and control of persistent $L$. monocytogenes are thus critical to assuring the microbial safety of farmstead dairy products.

Key words: Listeria monocytogenes, on-farm dairy production, automated ribotyping

\section{INTRODUCTION}

Listeria monocytogenes is not only a human foodborne pathogen, but also causes disease in a number of animal species, most commonly in farm ruminants (goats, sheep, and cattle). Interestingly, sheep seem more susceptible to L. monocytogenes than cattle (Wagner et al., 2005). Although human listeriosis is rare and only 2,500 human listeriosis cases are estimated to occur in the United States annually, it represents a severe disease with a case fatality rate of approximately $20 \%$ (Mead et al., 1999). Even though a risk assessment in the United States estimated that the majority of human listeriosis cases are caused by contaminated ready-toeat (RTE) meat products (FDA, 2003), RTE dairy products have been linked to multiple human listeriosis cases. For example, human listeriosis outbreaks have been linked to consumption of contaminated Hispanicstyle cheese in 1985 and 2000 in the United States (Linnan et al., 1988; MacDonald et al., 2005), contaminated soft cheese in Switzerland (Büla et al., 1995; Ryser, 1999a), and contaminated butter in Finland (Lyytikainen et al., 2000). Although $L$. monocytogenes is found in many environments, and thus is sometimes referred to as ubiquitous, it appears to be more prevalent in dairy farm environments than in most other environments. For example, Nightingale et al. (2004) found 22.2 and $16.8 \%$ prevalence of $L$. monocytogenes on cattle and small ruminant farms, respectively, in New York and adjacent states, whereas the prevalence in urban and natural environments in New York State was found to be markedly lower $(7.5$ and $1.4 \%$, respectively; Sauders et al., 2006).

Although $L$. monocytogenes is effectively inactivated by pasteurization, postprocessing contamination of RTE food and dairy products has been well established 
and control of L. monocytogenes in processing plant environments is thus critical (Silva et al., 2003; Kabuki et al., 2004). Molecular subtyping methods such as ribotyping or pulsed-field gel electrophoresis (Wiedmann, 2002) have been particularly critical in characterizing L. monocytogenes contamination patterns and transmission. For example, these techniques have shown that specific subtypes can often persist over time in a given processing-plant environment (Hoffman et al., 2003; Lappi et al., 2004; Thimothe et al., 2004), and that these persistent subtypes can cross-contaminate RTE food products after production (Thimothe et al., 2004). Interestingly, these molecular subtyping methods have also shown that at least some of the L. monocytogenes subtypes found on dairy farms may be indistinguishable from human disease-associated subtypes (Borucki et al., 2004; Nightingale et al., 2004), indicating the potential of dairy farms to serve as reservoirs of human disease-associated $L$. monocytogenes.

Based on the often-high L. monocytogenes prevalence as well as presence of human disease-associated subtypes on ruminant farms and the reemerging popularity of farmstead dairy processing facilities (Wagner et al., 2005), the objective of this study was to use classical microbiological techniques and molecular subtyping to characterize $L$. monocytogenes ecology and transmission on a sheep farm and an associated farmstead dairy production facility.

\section{MATERIALS AND METHODS}

\section{Description of Sheep Farm, Milking Operations, and Farmstead Dairy Processing Facility}

This study was conducted on a sheep farm with an associated farmstead dairy processing facility in the northeastern United States. The sheep farm included approximately 1,000 Finn $\times$ Dorset $\times$ East Friesian sheep whose milk was used for production of sheep-milk dairy products (e.g., cheese, yogurt, cheese spreads) on the farmstead dairy processing facility. Approximately 300 to 400 ewes on the farm were milked. All livestock, including rams and lambs, were housed in barns close $(\sim 100 \mathrm{~m})$ to the farmstead dairy processing facility. Livestock grazed on pastures close to the barns and the dairy processing facility. In addition, animals were also fed silage year-round.

The milking parlor was housed in a building separate from the barns; this building also included the blue cheese aging and storage rooms, which were included in the sampling scheme (sampling site E31; see Table A1 in the Appendix for a complete description of all sampling sites). Ewes were milked twice a day in a double-24 milking parlor. There were 2 floor drains at both ends of the milking pit, one in the parlor (sampling site D20) and one under the parlor bulk tank (D22). Sheep milk was pumped from this tank into a transport tank, which was moved with a forklift to the processing facility where milk was then pumped into the sheep milk storage tank.

In addition to the sheep milk, the dairy processing facility received cow milk from an outside source, delivered by a milk truck directly to the processing facility and pumped into a separate bulk tank located next to the bulk tank used for the sheep milk. The processing facility specifically produced sheep milk cheese, mixed sheep and cow milk Camembert, mixed sheep and cow milk cheese spreads, and sheep milk yogurts. The dairy processing facility included a main production room with 2 windows on one end (windows sills in the production room side were sampling site E24; see Table A1) and a glass-walled office overlooking the production area (site E28 is the production-room side of these windows). In addition, the processing facility included 9 coolers for cheese ripening and storage (sites D8, E9, E10; D26 and E27 were inside the coolers), a shipping cooler (site D12 was a drain in this cooler), an office, a bulk tank room (site D2 was a drain in this room) with one tank each for cow and sheep milk (site E1 was underneath the sheep milk bulk tank), and a door leading to a loading area where the milk truck parks, a clean-in-place room (E4), a storage room (site E3 was the doorway between these 2 rooms), and a cheesewrapping area (D11). The blue cheese production area (sites D13, D29, E30) was separate from, but attached to, the main dairy production area; the blue cheese area had a separate entrance from the outside. There was also a packing/shipping area housed in the same building as the dairy processing facility, which was separated from the cheese-production areas by a set of glass doors. There was a footbath (sites E15 and E16 were the floor before and after this footbath) at the entrance from the packing/shipping area into the dairy processing facility, which represents the single entrance into the processing facility. All visitors had to wear overclothing (e.g., rubber clogs, lab coats, hairnets) provided by the facility.

\section{Sample Collection and Testing}

Environmental sponge samples for $L$. monocytogenes testing were collected from various sites in the farm milking area and the dairy processing facility between July 2002 and April 2006. Sampling sites included drains, floor areas, equipment surfaces, walls and doorways (see Table A1). Samples were collected every 1 to 4 mo for a total of 29 separate dates. Initially, sponge samples were collected at 22 sampling sites, including 19 sites in the processing facility and 3 sites in the 
farm's milking parlor; depending on the location, some sites were removed after at least 3 samplings revealed no samples positive for $L$. monocytogenes or putative other Listeria spp. In addition, some sites were added later during the study (see Table A1 in the Appendix).

Swabs were collected as previously described (Lappi et al., 2004; Thimothe et al., 2004) using sterile gloves and a gamma-irradiated sampling sponge moistened with $10 \mathrm{~mL}$ of neutralizing buffer (Hardy Diagnostics, Santa Maria, CA). Environmental sponge samples were shipped to the laboratory under refrigeration and processed on the day of receipt, as described by Lappi et al. (2004) and Thimothe et al. (2004) with minor modifications as described below. Briefly, sponges were added to $100 \mathrm{~mL}$ of Listeria enrichment broth (Difco, Becton Dickinson, Sparks, MD), stomached in a Stomacher 400 (Seward, London, UK) for $60 \mathrm{~s}$, and incubated at $30^{\circ} \mathrm{C}$ for $48 \mathrm{~h}$. Fifty microliters of the enrichment culture was plated on Oxford agar (Difco, Becton Dickinson) after 24 and $48 \mathrm{~h}$ of enrichment. Oxford plates were incubated at $30^{\circ} \mathrm{C}$ for $48 \mathrm{~h}$ and up to 4 colonies showing characteristic Listeria-like morphology were subsequently streaked onto Listeria monocytogenes plating media (LMPM; BioSynth Biochemica and Synthetica, Naperville, IL) to identify isolates that showed a blue-green colorimetric reaction and morphology characteristic of $L$. monocytogenes and $L$. ivanovii (Restaino et al., 1999). If putative $L$. monocytogenes or $L$. ivanovii isolates were obtained from a given sample, 1 isolate was characterized by automated ribotyping as described below and a sample was classified as positive for $L$. monocytogenes if this isolate was identified as $L$. monocytogenes (in fact, all isolates that showed a bluegreen colorimetric reaction on LMPM were identified as $L$. monocytogenes). If, for a given sample, no isolates showed a blue-green colorimetric reaction typical for $L$. monocytogenes or Listeria ivanovii, but at least 1 isolate showed typical Listeria-like morphology and characteristics on LMPM (i.e., white color), the sample was classified as positive for putative Listeria spp. (other than $L$. monocytogenes or L. ivanovii).

\section{Automated Ribotyping}

Automated ribotyping was performed using the RiboPrinter system (DuPont-Qualicon, Wilmington, DE) as previously described (Hoffman et al., 2003). Briefly, this typing method involves $E c o$ RI digestion of chromosomal DNA followed by Southern hybridization with an Escherichia coli rRNA operon probe. Images are acquired with a charge-coupled device camera and processed using custom software that normalizes fragment pattern data for band intensity and relative band position based on the molecular weight marker. The RiboPrinter soft- ware also assigns DuPont identification numbers (ID; e.g., DUP-1061) to the ribotype pattern for an isolate if it matches an existing pattern in the DuPont Qualicon database with a similarity of at least 0.85 . All DuPont ID were confirmed by visual inspection. If an assigned DuPont ID included more than one distinct ribotype pattern (e.g., patterns differing by a single weak band) then each pattern was designated with an additional alphabetized letter (e.g., DUP-1059A and DUP-1059B). Ribotype patterns for isolates in this study are uploaded and available for comparison on the web-based database PathogenTracker (www.pathogentracker.net).

\section{RESULTS AND DISCUSSION}

A 3-yr longitudinal study of L. monocytogenes contamination patterns on a farmstead dairy processing facility and the associated dairy sheep facility was conducted to better understand the ecology and transmission of this pathogen in farmstead dairy production facilities. Our data indicated that i) $L$. monocytogenes and Listeria contamination on the operation studied did not show seasonal patterns of contamination; ii) in farmstead dairy facilities, $L$. monocytogenes present on the farm can largely be prevented from being introduced into the processing facility; and iii) L. monocytogenes can persist on farm and in processing areas, providing a potential high risk source for contamination.

\section{Seasonal Patterns of Contamination}

Among a total of 759 samples collected over 29 sampling dates, $L$. monocytogenes and putative Listeria spp. (other than L. monocytogenes and L. ivanovii) were isolated from 26 and 112 samples, respectively (representing prevalences of 3.4 and $14.8 \%$, respectively). Samples collected from the processing facility $(\mathrm{n}=674)$ showed $L$. monocytogenes and putative Listeria spp. prevalences of 2.7 and $13.9 \%$, respectively, whereas samples collected from the farm $(n=85$, including 82 environmental sponges from the milking parlor and 3 silage samples from the barns) showed $L$. monocytogenes and putative Listeria spp. prevalences of 9.4 and $21.2 \%$, respectively. A $\chi^{2}$ test showed that L. monocytogenes prevalence was significantly higher in farm samples compared with samples from the processing facility $(P<0.01)$. These findings are consistent with previous reports (Nightingale et al., 2004), which have shown considerable $L$. monocytogenes prevalences for ruminant farms $(20.1 \%$ prevalence based on 52 farms) as well as potentially low average prevalences $(<10 \%)$ in dairy production facilities (Cotton and White, 1992; Pritchard et al., 1995; Silva et al., 2003). 
Table 1. Seasonality of Listeria monocytogenes and Listeria spp. prevalence

\begin{tabular}{|c|c|c|c|}
\hline \multirow[b]{2}{*}{$\begin{array}{l}\text { Season }^{1} \\
\text { (samplings) }\end{array}$} & \multirow[b]{2}{*}{$\underset{\mathrm{n}}{\text { Samples, }}{ }^{2}$} & \multicolumn{2}{|c|}{ Prevalence (\%) } \\
\hline & & $\begin{array}{c}L . \\
\text { monocytogenes }\end{array}$ & $\begin{array}{l}\text { Listeria } \\
\text { spp. }^{3}\end{array}$ \\
\hline Winter $(\mathrm{n}=6)$ & 161 & 3.8 & 13.7 \\
\hline Spring $(\mathrm{n}=7)$ & 187 & 2.1 & 16.6 \\
\hline Summer $(n=6)$ & 158 & 3.8 & 13.9 \\
\hline Fall $(\mathrm{n}=10)$ & 253 & 4.0 & 14.6 \\
\hline
\end{tabular}

${ }^{1}$ Winter = December-February; spring = March-May; summer = June-August; and fall = September-November .

${ }^{2}$ Samples included in this analysis were obtained from both the processing facility and the milking parlor, including feed samples.

${ }^{3}$ This category represents putative Listeria species other than $L$. monocytogenes and Listeria ivanovii.

Overall, drains represented most of the samples positive for $L$. monocytogenes ( 15 of $26 L$. monocytogenes positive samples were obtained from drains), whereas only 1 sponge sample from equipment was positive for L. monocytogenes (sample E7). The L. monocytogenes prevalence was $5.3 \%$ in drain and floor samples (469 samples), $0 \%$ in samples from other environments (e.g., walls, windows, etc.; 75 samples), and $0.5 \%$ in equipment samples (212 samples). Listeria spp. prevalences for the same categories were 18.6, 4.0, and 9.4\% (these data encompass samples collected in both the processing operation and the milking parlor, but exclude the 3 feed samples tested). These data are consistent with previous studies that generally showed the highest prevalences of $L$. monocytogenes in drains and floors of dairy and food processing facilities (e.g., Gravani, 1999; Lappi et al., 2004).

When prevalence data were partitioned by season, where winter was defined as December through February, spring as March through May, summer as June through August, and fall as September to November, L. monocytogenes and Listeria spp. prevalences were very similar among seasons; $L$. monocytogenes prevalence ranged from 2.1 to $4 \%$, whereas Listeria spp. prevalence ranged from 13.7 to $16.6 \%$ (Table 1). Although previous studies on Listeria spp. prevalence in raw milk reported some evidence for seasonal variation (Gaya et al., 1996; Ryser, 1999b), these seasonal variations were only found to be statistically significant in one study on raw goat milk (Gaya et al., 1996), in which more samples positive for Listeria spp. were found in the fall and winter. Seasonal variations in Listeria prevalence might be related to silage feeding, with higher prevalences in months when silage is fed to animals (Ryser, 1999b). The fact that the dairy sheep in the farm studied here were fed silage year-round may thus provide an explanation for the lack of seasonality in Listeria spp. prevalences observed in our study.

\section{Transmission Between Farm and Processing Facility}

Although data provided initial evidence of lower $L$. monocytogenes prevalence in the processing facility compared with the farm, molecular subtyping data are critical to specifically understand $L$. monocytogenes transmission and ecology. To better understand the relationship between $L$. monocytogenes found on the sheep farm and the dairy processing area and the ecology of $L$. monocytogenes in these 2 areas, all $L$. monocytogenes isolates were characterized by automated EcoRI ribotyping, a commonly used and highly standardized molecular subtyping method for L. monocytogenes (e.g., Gray et al., 2004; Lappi et al., 2004). Overall, 8 different $E c o$ RI ribotypes were differentiated among the $26 \mathrm{~L}$. monocytogenes isolated (Table 2). Four ribotypes (DUP1038B, DUP-1039A, DUP-1042A, and DUP-18041) were isolated only from the farm (i.e., milking parlor; Figure 1), and 3 ribotypes (DUP-1030B, DUP-1044A, and DUP-1052A) were found only in samples collected from sites in the processing facility. Only 1 ribotype (DUP-1030A) was found both on the farm and within the processing facility (Figure 1); this ribotype was isolated only once in each environment. The initial source of the specific ribotypes found in the processing environment could not be determined; considering the ubiquitous nature of $L$. monocytogenes, a number of potential sources other than farm environments, including natu-

Table 2. Summary of ribotypes isolated from farm/milking parlor $(\mathrm{M})$ and dairy processing facility $(\mathrm{P})$ sites

\begin{tabular}{lll}
\hline Ribotype & $\begin{array}{l}\text { Isolates from } \\
\text { M and P (n) }\end{array}$ & \multicolumn{1}{c}{ Location of isolates (n) } \\
\hline $1052 \mathrm{~A}$ & $\mathrm{P}(15)$ & Drains (6), floor (5), door threshold (3), equipment (1) \\
$1039 \mathrm{~A}$ & $\mathrm{M}(4)$ & Drains (4) \\
$1030 \mathrm{~A}$ & $\mathrm{P}(1), \mathrm{M}(1)$ & Drains (2) \\
$1030 \mathrm{~B}$ & $\mathrm{P}(1)$ & Door threshold (1) \\
$1042 \mathrm{~A}$ & $\mathrm{M}(1)$ & Drain (1) \\
$1044 \mathrm{~A}$ & $\mathrm{P}(1)$ & Door threshold, main entry (1) \\
$1038 \mathrm{~B}$ & $\mathrm{M}(1)$ & Drain (1) \\
18041 & $\mathrm{M}(1)$ & Drain (1) \\
\hline
\end{tabular}




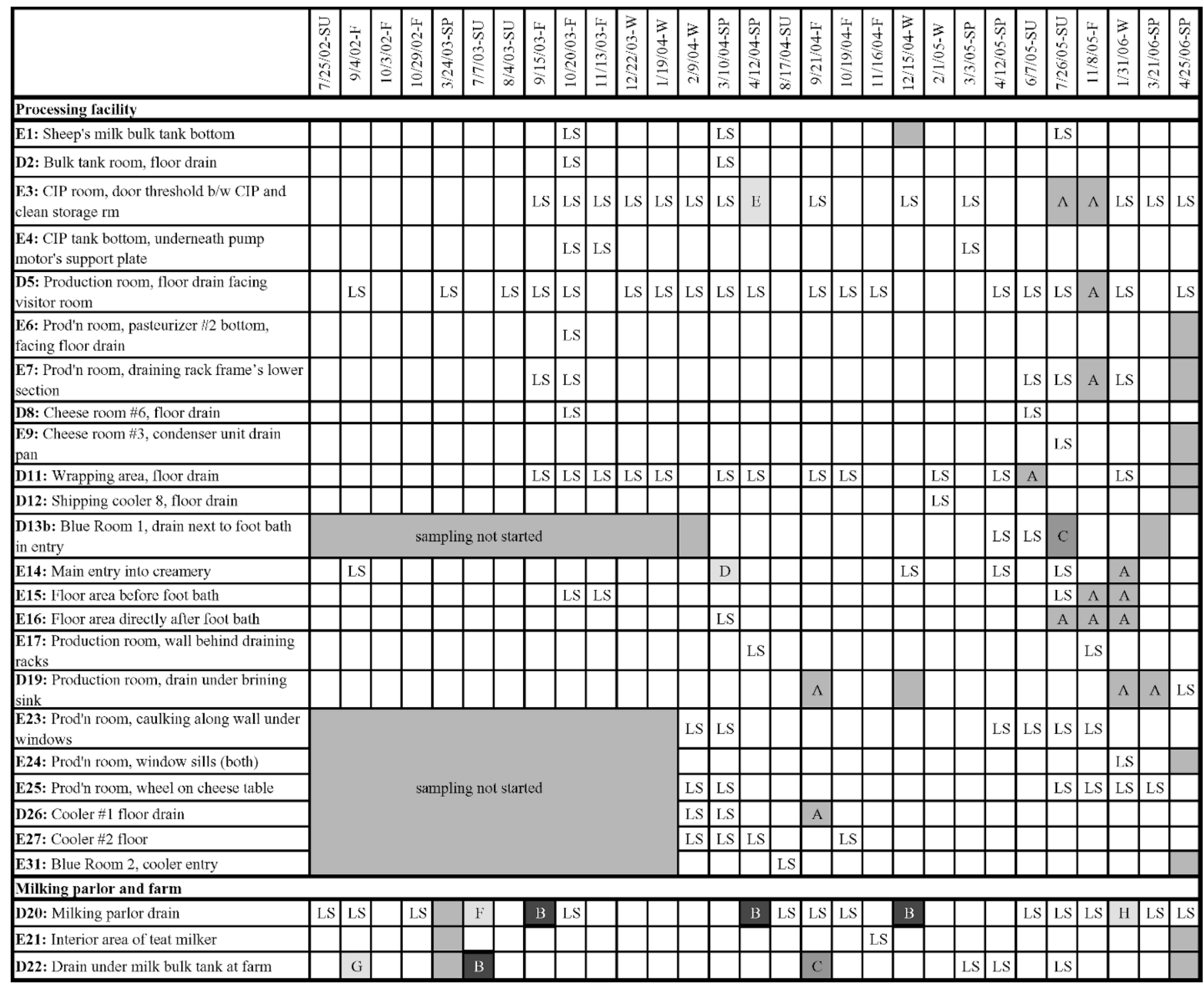

Figure 1. Summary of Listeria monocytogenes ribotypes and putative Listeria spp. isolated over 29 samplings in the dairy processing facility and associated farm. Sampling locations in the left hand column are designated with prefixes: D for drain sample, E for other environmental sample, and F for feed samples; detailed descriptions of all sampling sites, including sampling sites that never yielded $L$. monocytogenes or putative Listeria spp. (and, thus, are not included here) are found in Table A1 in the Appendix. Sampling dates are listed in the top row, and sampling seasons are indicated by different letters ( $\mathrm{W}=$ winter; $\mathrm{SP}=$ spring; $\mathrm{SU}=$ summer; $\mathrm{F}=$ fall). White boxes indicate samples that were negative for any Listeria spp.; boxes with "LS" indicate samples that yielded putative Listeria spp. (other than L. monocytogenes or Listeria ivanovii); differentially shaded boxes with letter codes indicate samples positive for L. monocytogenes; different EcoRI ribotypes are represented by different shades of grey; and ribotypes are indicated by different letters $(\mathrm{A}=\mathrm{DUP}-1052 \mathrm{~A}$; B = DUP1039A; C = DUP-1030A; D = DUP-1044A; E = DUP-1030B; F = DUP 18041; G = DUP-1038B; H = DUP-1042A); ribotypes that only occurred once are indicated by boxes that show light grey dotting (e.g., DUP-1030B in sample E3 on 4/12/04). Grey boxes with no lettering indicate that no samples were collected. Data for the 2 feed samples (collected on 7/25/02) that were positive for Listeria spp. are not shown.

ral and urban environments, could be responsible for introduction of $L$. monocytogenes into food and food processing environments (Sauders et al., 2006). Overall, our data indicate very limited transfer of $L$. monocytogenes from the farm environment to the dairy processing environment and vice versa in the specific farmstead dairy processing operation studied here. Al- though other farmstead operations may show more transfer of L. monocytogenes or other foodborne pathogens (e.g., Staphylococcus aureus; Jørgensen et al., 2005) between farm and processing environments, our data indicate that it is possible to minimize pathogen transmission from farm to processing sites on farmstead dairy processing facilities. 


\section{Persistence of L. monocytogenes on the Farm and in Processing Areas}

Molecular subtyping data provided clear evidence that different $L$. monocytogenes subtypes persisted in each farm/milking parlor environment and the dairy processing facility. Specifically, 4 of the $8 \mathrm{~L}$. monocytogenes isolates from the milking parlor represented ribotype DUP-1039A; this ribotype was isolated over a 15mo period (June 2003 through December 2004). Similarly, DUP-1052A was the predominant ribotype found in the dairy processing facility, representing 15 of the 18 isolates obtained there; this ribotype was isolated over an 18-mo period (September 2004 through March 2006). All other ribotypes except DUP-1030A (which was isolated once from the farm and once from the dairy processing facility) were only found once, indicating sporadic contamination events. These findings are consistent with previous studies that reported persistence of specific $L$. monocytogenes subtypes in food and dairy processing facilities (e.g., Kabuki et al., 2004; Lappi et al., 2004) as well as in other environments, such as retail operations (Sauders et al., 2004) and urban environments (Sauders et al., 2006). Interestingly, both DUP-1052A and DUP-1039A have previously been shown to persist in smoked seafood processing plants (Thimothe et al., 2004), indicating perhaps that L. monocytogenes isolates with these ribotypes may have unique characteristics that make them more likely to establish persistent populations. Persistence of distinct L. monocytogenes subtypes in the farm or milking parlor and the dairy processing plant environment further confirms efficient separation and prevention of crosscontamination between these areas in the facility studied here.

Molecular subtyping data provided evidence that specific areas within the processing facility appeared to be critical for dispersal of the persistent subtype DUP1052A. Although DUP-1052A was isolated from 9 different sampling sites in the processing facility, including 4 different drains (Figure 1 and Table 2), contamination with this specific subtype showed increased prevalence in the latter part of 2005 and in early 2006; contamination during this time seemed to be localized in sites (E15 and E16) that were close to the footbath located at the entrance to the dairy processing facility from the packing/shipping area. When these data were used to alert processing plant staff to take corrective action in this area, including increased monitoring of sanitizer concentrations of the footbath and increased frequency of sanitizer changes, the prevalence of $L$. monocytogenes DUP-1052A in March and April 2006 was clearly reduced (Figure 1). These findings are consistent with previous reports indicating the importance of monitor- ing footbaths (FAO, 1999; Tompkin et al., 1999) and further support the use of molecular subtyping for identifying specific problem areas (e.g., Lunden et al., 2002; Lappi et al., 2004). Control of persistent subtypes is particularly critical because these persistent subtypes have often been shown to present a particular risk for contamination of finished food products (Lappi et al., 2004). More broadly, our findings support the importance of a stringent Listeria control program even in small processing plants, including regular environmental monitoring and stringent sanitation programs (including sanitation standard operating procedures), as well as measures to prevent and control persistent Listeria contamination in niches in a plant (Tompkin et al., 1999; Tompkin, 2002).

\section{ACKNOWLEDGMENTS}

This project was supported by the Cooperative State Research, Education, and Extension Service, US Department of Agriculture Integrated Food Safety Grant (No. 2003-51110-01712). Any opinions, findings, conclusions, or recommendations expressed in this publication are those of the authors and do not necessarily reflect the view of the USDA. The authors gratefully acknowledge the staff and management of the farmstead dairy processing facility used in this study, without whose assistance and cooperation this study would not have been possible. Thanks also go to K. Lyles for ribotyping, as well as students and staff at the Cornell Food Safety Laboratory who assisted with sample processing.

\section{REFERENCES}

Borucki, M. K., J. Reynolds, C. C. Gay, K. L. McElwain, S. H. Kim, D. P. Knowles, and J. Hu. 2004. Dairy farm reservoir of Listeria monocytogenes sporadic and epidemic strains. J. Food Prot. 67:2496-2499.

Büla, C. J., J. Bille, and M. P. Glauser. 1995. An epidemic of foodborne listeriosis in western Switzerland: Description of 57 cases involving adults. Clin. Infect. Dis. 20:66-72.

Cotton, L. N., and C. H. White. 1992. Listeria monocytogenes, Yersinia pestis, and Salmonella in dairy plant environments. J. Dairy Sci. 75:51-57.

Food and Agriculture Organization of the United Nations (FAO). 1999. FAO Expert consultation on the trade impact of Listeria in fish products, Annex III_Control Guidelines. http://www.fao.org/ docrep/003/x3018e/x3018e12.htm Accessed Feb. 23, 2007.

Gaya, P., C. Saralegui, M. Medina, and M. Nunez. 1996. Occurrence of Listeria monocytogenes and other Listeria spp. in raw caprine milk. J. Dairy Sci. 79:1936-1941.

Gravani, R. 1999. Incidence and control of Listeria in food-processing facilities. Pages 657-709 in Listeria, Listeriosis and Food Safety. 2nd ed. E. T. Ryser and E. H. Marth, ed. Marcel Dekker, Inc., New York, NY.

Gray, M. J., R. N. Zadoks, E. D. Fortes, B. Dogan, S. Cai, Y. Chen, V. N. Scott, D. E. Gombas, K. J. Boor, and M. Wiedmann. 2004. Listeria monocytogenes isolates from foods and humans form distinct but overlapping populations. Appl. Environ. Microbiol. 70:5833-5841. 
Hoffman, A. D., K. L. Gall, D. M. Norton, and M. Wiedmann. 2003. Listeria monocytogenes contamination patterns for the smoked fish processing environment and for raw fish. J. Food Prot. $66: 52-60$.

Jørgensen, H. J., T. Mørk, and L. M. Rørvik. 2005. The occurrence of Staphylococcus aureus on a farm with small-scale production of raw milk cheese. J. Dairy Sci. 88:3810-3817.

Kabuki, D. Y., Y. Kuaye, M. Wiedmann, and K. Boor. 2004. Molecular subtyping and tracking of Listeria monocytogenes in Latin-style fresh-cheese processing plants. J. Dairy Sci. 87:2803-2812.

Lappi, V. R., J. Thimothe, K. K. Nightingale, K. Gall, V. N. Scott, and M. Wiedmann. 2004. Longitudinal studies on Listeria in smoked fish plants: Impact of intervention strategies on contamination patterns. J. Food Prot. 67:2500-2514.

Linnan, M. J., L. Mascola, X. D. Lou, V. Goulet, S. May, C. Salminen, D. W. Hird, M. L. Yonekura, P. Hayes, R. Weaver, A. Audurier, B. D. Plikaytis, S. L. Fannin, A. Kleks, and C. V. Broome. 1988. Epidemic listeriosis associated with Mexican-style cheese. N. Engl. J. Med. 319:823-828.

Lunden, J. M., T. J. Autio, and H. J. Korkeala. 2002. Transfer of persistent Listeria monocytogenes contamination between foodprocessing plants associated with a dicing machine. J. Food Prot. 65:1129-1133.

Lyytikainen, O., T. Autio, R. Maijala, P. Ruutu, T. Honkanen-Buzalski, M. Miettinen, M. Hatakka, J. Mikkola, V. J. Anttila, T. Johansson, L. Rantala, T. Aalto, H. Korkeala, and A. Siitonen. 2000. An outbreak of Listeria monocytogenes serotype 3a infections from butter in Finland. J. Infect. Dis. 181:1838-1841.

MacDonald, P. D., R. E. Whitwam, J. D. Boggs, J. N. MacCormack, K. L. Anderson, J. W. Reardon, J. R. Saah, L. M. Graves, S. B. Hunter, and J. Sobel. 2005. Outbreak of listeriosis among Mexican immigrants as a result of consumption of illicitly produced Mexican-style cheese. Clin. Infect. Dis. 40:677-682.

Mead, P. S., L. Slutsker, V. Dietz, L. F. McCaig, J. S. Bresee, C. Shapiro, P. M. Griffin, and R. V. Tauxe. 1999. Food-related illness and death in the United States. Emerg. Infect. Dis. 5:607-625.

Nightingale, K. K., Y. H. Schukken, C. R. Nightingale, E. D. Fortes, A. J. Ho, Z. Her, Y. T. Grohn, P. L. McDonough, and M. Wiedmann. 2004. Ecology and transmission of Listeria monocytogenes infecting ruminants and in the farm environment. Appl. Environ. Microbiol. 70:4458-4467.

Pritchard, T. J., K. J. Flanders, and C. W. Donnelly. 1995. Comparison of the incidence of Listeria on equipment versus environmental sites within dairy processing plants. Int. J. Food Microbiol. 26:375-384.

Restaino, L., E. W. Frampton, R. M. Irbe, G. Schabert, and H. Spitz. 1999. Isolation and detection of Listeria monocytogenes using fluorogenic and chromogenic substrates for phosphatidylinositolspecific phospholipase C. J. Food Prot. 62:244-251.

Ryser, E. T. 1999a. Foodborne listeriosis. Pages 299-358 in Listeria, Listeriosis and Food Safety. 2nd ed. E. T. Ryser and E. H. Marth, ed. Marcel Dekker, Inc., New York, NY.

Ryser, E. T. 1999b. Incidence and behavior of Listeria monocytogenes in unfermented dairy products. Pages 359-409 in Listeria, Listeriosis and Food Safety. 2nd ed. E. T. Ryser and E. H. Marth, ed. Marcel Dekker, Inc., New York, NY.

Sauders, B. D., M. Z. Durak, E. Fortes, K. Windham, Y. Schukken, A. J. Lembo, Jr., B. Akey, K. K. Nightingale, and M. Wiedmann. 2006. Molecular characterization of Listeria monocytogenes from natural and urban environments. J. Food Prot. 69:93-105.

Sauders, B. D., K. Mangione, C. Vincent, J. Schermerhorn, C. M. Farchione, N. B. Dumas, D. Bopp, L. Kornstein, E. D. Fortes, K. Windham, and M. Wiedmann. 2004. Distribution of Listeria monocytogenes molecular subtypes among human and food isolates from New York State shows persistence of human disease associated $L$. monocytogenes strains in retail environments. J. Food Prot. 67:1417-1428.

Silva, I. M. M., R. C. C. Almeida, M. A. O. Alves, and P. F. Almeida. 2003. Occurrence of Listeria spp. in critical control points and the environment of Minas Frescal cheese processing. Int. J. Food Microbiol. 81:241-248.

Thimothe, J., K. K. Nightingale, K. Gall, V. N. Scott, and M. Wiedmann. 2004. Tracking of Listeria monocytogenes in smoked fish processing plants. J. Food Prot. 67:328-341.

Tompkin, R. B. 2002. Control of Listeria monocytogenes in the foodprocessing environment. J. Food Prot. 65:709-725.

Tompkin, R. B., V. N. Scott, D. T. Bernard, W. H. Sveum, and K. S. Gombas. 1999. Guidelines to prevent post-processing contamination from Listeria monocytogenes. Dairy Food Environ. Sanit. 19:551-562.

US Food and Drug Administration (FDA), Center for Food Safety and Applied Nutrition, USDA, Food Safety and Inspection Service, and the Centers for Disease Control and Prevention. 2003. Quantitative assessment of relative risk to public health from foodborne Listeria monocytogenes among selected categories of ready-to-eat foods. http://www.foodsafety.gov/ dms/lmr2-toc. html Accessed Feb. 23, 2007.

Wagner, M., D. Melzner, Z. Bago, P. Winter, M. Egerbacher, F Schilcher, A. Zangana, and D. Schoder. 2005. Outbreak of clinical listeriosis in sheep: Evaluation from possible contamination routes from feed to raw produce and humans. J. Vet. Med. $52: 278-283$

Wiedmann, M. 2002. Molecular subtyping methods for Listeria monocytogenes. J. AOAC Int. 85:524-531. 


\section{APPENDIX}

Table A1. Sampling sites used in study ${ }^{1}$

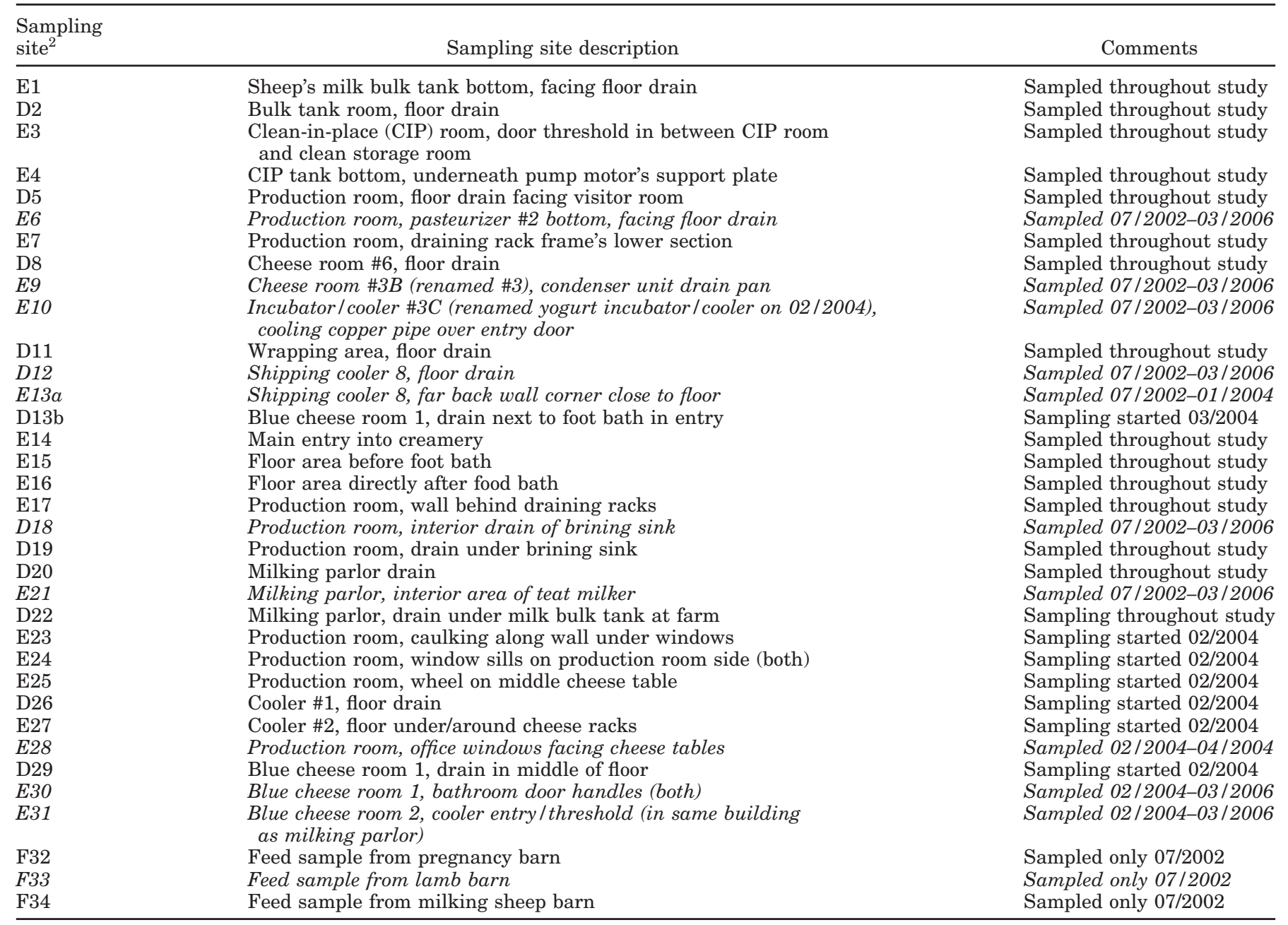

${ }^{1}$ Italic font indicates sites that were removed from sampling scheme if samples were rarely positive and negative for at least 3 consecutive samplings.

${ }^{2}$ Samples E1, E4, E6, E7, E9, E10, E21, and E25 are designated "equipment" samples. 